\title{
Aortic valve repair: Defining the patient population and timing of the intervention
}

Rakesh M. Suri, MD, DPhil, and Hartzell V. Schaff, MD

See related article on pages 1913-20 in the

November 2014 issue.

Unlike the scientific rationale justifying early mitral valve repair for asymptomatic patients with severe degenerative mitral regurgitation, ${ }^{1}$ a more stringent threshold limits the recommendation for surgery in the setting of severe aortic regurgitation (AR). ${ }^{2}$ This is in part due to the fact that aortic valve replacement (AVR) is often performed rather than valve repair. Current consensus statements recommend earlier AVR in patients with asymptomatic severe AR (ie, stage C) when ejection fraction is $<50 \%$ (class I), at the time of another cardiac surgical procedure (class I), or when or left ventricular end systolic dimension is $>50 \mathrm{~mm}$ (class IIa). Caution is given that “...performance of aortic valve $(\mathrm{AV})$ repair should be concentrated in those centers with proven expertise in the procedure." 2

De Meester and colleagues ${ }^{3}$ analyzed 44 propensitymatched patient pairs who underwent surgical correction of severe AR by AV repair (mean age 65 years) versus AVR (mean age 63 years) between 1995 and 2012. They found similar early mortality ( $2 \%$ for repair vs $5 \%$ for AVR; $P=.56$ ) but better late survival after AV repair than after AVR (87\% vs $60 \% ; P=.007)$. Repair was an independent predictor of improved late survival, but was associated with a "slight" increase in reoperation rate at 9 years $(8 \%$ vs $2 \% ; P=.35)$. The authors concluded that "AV repair significantly improves postoperative outcomes ... and whenever feasible, should probably be the preferred mode of surgical correction."

Is this new? $?^{3-7}$ Amongst 331 patients (mean age 53 years) who underwent elective AV repair for AR at the Mayo Clinic, in-hospital mortality was $0.6 \%$ (2 out of 332 patients), and overall survival was $91 \%$ and $81 \%$ at 5 and 10 years, respectively. Patients with an ejection fraction $<50 \%$ and left ventricular end systolic dimension $>50 \mathrm{~mm}$ had significantly higher odds of late death (hazard ratio, $3.46[P<.001]$ and hazard ratio, $2.08[P=.036]){ }^{4}$

\footnotetext{
From the Division of Cardiovascular Surgery, Mayo Clinic, Rochester, Minn. Disclosures: Authors have nothing to disclose with regard to commercial support. Received for publication Sept 23, 2014; accepted for publication Oct 5, 2014 Address for reprints: Rakesh M. Suri, MD, DPhil, Division of Cardiovascular Surgery, Mayo Clinic College of Medicine, 200 First St, SW, Rochester, MN 55905 (E-mail: suri.rakesh@mayo.edu).

J Thorac Cardiovasc Surg 2014;148:2477-8

0022-5223/\$36.00

Copyright (c) 2014 by The American Association for Thoracic Surgery http://dx.doi.org/10.1016/j.jtcvs.2014.10.020
}

The risk of $\mathrm{AV}$ reoperation was $10 \%$ and $21 \%$ at 5 and 10 years, respectively. But when we specifically compared outcomes of AV repair in patients with bicuspid aortic valves to an age- and sex-matched cohort who had AVR with heterograft bioprostheses, we found no significant difference in 10 -year survival $(72 \%$ vs $79 \% ; P=.13)$ or freedom from reoperation between groups $(90 \%$ vs $98 \%$ and $72 \%$ vs $64 \%$ in 5 and 10 years, respectively; $P<.12$ ).

Are comparisons between the practices of aortic and mitral valve repair legitimate? Recent advancements have occurred in the understanding of AV cusp anatomy, echocardiographic predictors of AV repair success (based on cusp dimensions and coaptation height), and AV repair techniques. ${ }^{3,9-13}$ Despite this progress, the disciplines of aortic and mitral valve repair may not be entirely analogous. First, AV repair strategies remain heterogeneously applied amongst surgeons and institutions. Second, whereas leaflet tissue quality is less frequently a concern in patients with degenerative mitral valve regurgitation (repair $>98 \%$ at experienced centers and reoperation $<1 \% / y$ ); aortic cusp pliability, mobility, and calcification are less predictable and all dramatically affect AV repair performance and durability. Third, whereas excess leaflet tissue most often exists in degenerative mitral valve disease, allowing surgeons to trim, shape, and support valve leaflets, the relative paucity of AV cusp tissue may at times preclude the performance of $\mathrm{AV}$ repair, particularly in the presence of cusp restriction, thickening, or fenestration. Fourth, the frequency with which bicuspid AV variations are encountered contribute to AV repair remaining a highly technical and judgment-dependent procedure. Furthermore, unlike a repaired mitral valve, a repaired bicuspid AV remains at risk for late calcification and stenosis.

How can we explain the finding of improved survival following AV repair? Although mitral valve repair preserves ventriculovalvular continuity and presumably maintains normal contractile function, ${ }^{14}$ these same connections with the ventricle are absent in patients undergoing AV repair. A rigidly fixed aortic annulus, as would occur following AVR with a stented valve substitute, might theoretically cause physiologic alterations; however, this is merely speculative. A more plausible explanation is the cumulative physiologic effect of living with a degenerating bioprosthesis. Although primary failure of bioprostheses may progress rapidly, many patients endure years of exposure to hemodynamically significant valvular regurgitation, stenosis, or both until structural valve failure is diagnosed and re-replacement is recommended ${ }^{15}$ (Figure 1). 


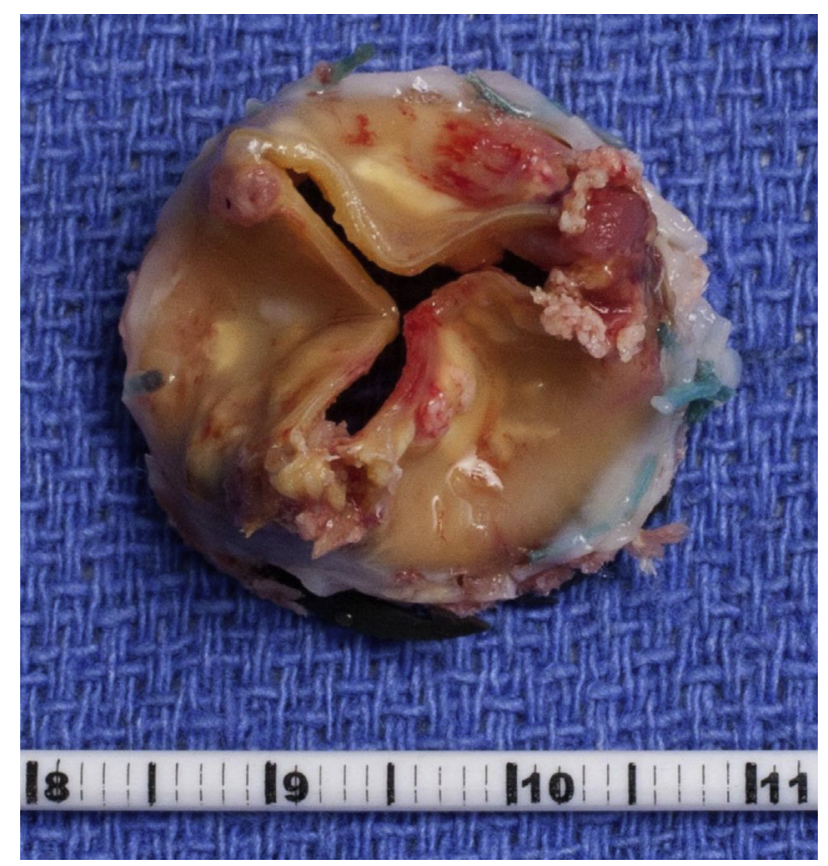

FIGURE 1. Aortic bovine pericardial prosthesis explanted 3 years following insertion.

Will AV repair become more widely available at heart valve centers? We recently proposed ${ }^{4}$ that several populations might preferentially benefit from the more frequent performance of $\mathrm{AV}$ repair. First, young patients with bicuspid AR had fewer reoperations and longer median time to repair failure in our experience. Additionally, only $16 \%$ of patients with intact $\mathrm{AV}$ repair required warfarin (6\% with bicuspid repair alone), which is an attractive lifestyle advantage to young, active patients and women of childbearing age. Second, nonelderly patients undergoing other cardiac surgical procedures with concomitant moderate aortic regurgitation benefit hemodynamically from aortic annular reduction. Third, those with isolated AV cusp perforation can often undergo localized pericardial patch repair, which we have found to be highly effective and durable. In contrast, the benefits of complex AV repair in elderly patients with poor cusp tissue quality are less obvious in comparison to bioprosthetic AVR.

\section{CONCLUSIONS}

Contemporary evidence indicates that $\mathrm{AV}$ repair for $\mathrm{AR}$ can be performed with very low $(<1 \%)$ mortality risk at experienced surgical centers, is as durable as AVR, and improves patient survival when performed before the onset of left ventricular dilation or dysfunction. Freedom from anticoagulation and avoidance of exposure to the cumulative effects of bioprosthetic AVR senescence make AV repair an attractive option for young patients with thin, pliable, and mobile aortic cusps; particularly those with bicuspid $\mathrm{AV}$ regurgitation.

\section{References}

1. Suri RM, Vanoverschelde JL, Grigioni F, Schaff HV, Tribouilloy C, Avierinos JF, et al. Association between early surgical intervention vs watchful waiting and outcomes for mitral regurgitation due to flail mitral valve leaflets. JAMA. 2013;310:609-16.

2. Nishimura RA, Otto CM, Bonow RO, Carabello BA, Erwin JP III, Guyton RA, et al. 2014 AHA/ACC guideline for the management of patients with valvular heart disease: executive summary: a report of the American College of Cardiology/American Heart Association Task Force on Practice Guidelines [erratum in J Am Coll Cardiol. 2014;63:2489]. J Am Coll Cardiol. 2014;63: 2438-88.

3. de Meester C, Pasquet A, Gerber BL, Vancraeynest D, Noirhomme P, El Khoury G, et al. Valve repair improves the outcome of surgery for chronic severe aortic regurgitation: a propensity score analysis. J Thorac Cardiovasc Surg. 2014;148:1913-20.

4. Sharma V, Suri RM, Dearani JA, Burkhart HM, Park SJ, Joyce LD, et al. Expanding relevance of aortic valve repair-is earlier operation indicated? J Thorac Cardiovasc Surg. 2014;147:100-7.

5. Gleason TG. Bicuspid aortic valve repair by complete conversion from "raphe'd" (type 1) to "symmetric" (type 0) morphology. J Thorac Cardiovasc Surg. 2014;148:2862-8.

6. Boodhwani M, El Khoury G. Aortic valve repair: indications and outcomes. Curr Cardiol Rep. 2014;16:490.

7. Kari FA, Siepe M, Sievers HH, Beyersdorf F. Repair of the regurgitant bicuspid or tricuspid aortic valve: background, principles, and outcomes. Circulation. 2013;128:854-63.

8. Ashikhmina E, Sundt TM III, Dearani JA, Connolly HM, Li Z, Schaff HV. Repair of the bicuspid aortic valve: a viable alternative to replacement with a bioprosthesis. J Thorac Cardiovasc Surg. 2010;139:1395-401.

9. Tamer S, de Kerchove L, Glineur D, El Khoury G. Video-atlas of aortic valve repair. Ann Cardiothorac Surg. 2013;2:124-6.

10. Navarra E, El Khoury G, Glineur D, Boodhwani M, Van Dyck M, Vanoverschelde JL, et al. Effect of annulus dimension and annuloplasty on bicuspid aortic valve repair. Eur J Cardiothorac Surg. 2013;44:316-22; discussion 22-3.

11. Kearney K, Croce B, Harris R. Aortic valve repair. Ann Cardiothorac Surg. 2013; 2:146.

12. El Khoury G, de Kerchove L. Principles of aortic valve repair. J Thorac Cardiovasc Surg. 2013;145(3 Suppl):S26-9.

13. Schafers HJ. Aortic annuloplasty: a new aspect of aortic valve repair. Eur J Cardiothorac Surg. 2012;41:1124-5.

14. Suri RM, Schaff HV, Dearani JA, Sundt TM III, Daly RC, Mullany CJ, et al. Survival advantage and improved durability of mitral repair for leaflet prolapse subsets in the current era. Ann Thorac Surg. 2006;82:819-26.

15. Smedira NG, Blackstone EH, Roselli EE, Laffey CC, Cosgrove DM. Are allografts the biologic valve of choice for aortic valve replacement in nonelderly patients? Comparison of explantation for structural valve deterioration of allograft and pericardial prostheses. J Thorac Cardiovasc Surg. 2006;131:558-64.e4. 